\title{
Glutamine rapidly induces the expression of key transcription factor genes involved in nitrogen and stress responses in rice roots
}

\author{
Chia-Cheng Kan ${ }^{\dagger}$, Tsui-Yun Chung ${ }^{\dagger}$, Yan-An Juo and Ming-Hsiun Hsieh ${ }^{*}$
}

\begin{abstract}
Background: Glutamine is a major amino donor for the synthesis of amino acids, nucleotides, and other nitrogen-containing compounds in all organisms. In addition to its role in nutrition and metabolism, glutamine can also function as a signaling molecule in bacteria, yeast, and humans. By contrast, the functions of glutamine in nutrition and as a signaling molecule remain unclear in plants.

Results: We demonstrated that glutamine could effectively support the growth of rice seedlings. In glutaminetreated rice roots, the glutamine contents increased dramatically, whereas levels of glutamate remained relatively constant. Transcriptome analysis of rice roots revealed that glutamine induced the expression of at least 35 genes involved in metabolism, transport, signal transduction, and stress responses within 30 min. Interestingly, 10 of the 35 early glutamine responsive genes encode putative transcription factors, including two LBD37-like genes that are involved in the regulation of nitrogen metabolism. Glutamine also rapidly induced the expression of the DREBTA, IRO2, and NAC5 transcription factor genes, which are involved in the regulation of stress responses.
\end{abstract}

Conclusions: In addition to its role as a metabolic fuel, glutamine may also function as a signaling molecule to regulate gene expression in plants. The rapid induction of transcription factor genes suggests that glutamine may efficiently amplify its signal and interact with the other signal transduction pathways to regulate plant growth and stress responses. Thus, glutamine is a functional amino acid that plays important roles in plant nutrition and signal transduction.

Keywords: Amino acid, Gene expression, Glutamine, Rice, Signal transduction, Transcription factor

\section{Background}

Most plants use inorganic nitrogen nitrate and ammonium as their primary nitrogen source [1]. Nitrate taken up from the soil is reduced to nitrite by nitrate reductase. Nitrite is very toxic and in the plant cell nitrite is quickly reduced to ammonium by nitrite reductase. Ammonium derived from nitrate or directly absorbed from the soil can be assimilated into glutamine and glutamate via the glutamine synthetase (GS)/glutamineoxoglutarate aminotransferase (GOGAT) cycle [2]. In the GS/GOGAT cycle, GS catalyzes the synthesis of glutamine from ammonium and glutamate and GOGAT catalyzes the transfer of the amide group of glutamine to oxoglutarate to synthesize glutamate. The GS/GOGAT

\footnotetext{
* Correspondence: ming@gate.sinica.edu.tw

${ }^{\dagger}$ Equal contributors

Institute of Plant and Microbial Biology, Academia Sinica, Taipei 11529,

Taiwan
}

cycle is the major pathway for the primary nitrogen assimilation in plants [3]. In addition to primary nitrogen assimilation, GS and GOGAT also participate in the remobilization of nitrogen-containing compounds and the assimilation of large amounts of ammonium generated by photorespiration in C3 plants [4].

Plants can also take up organic nitrogen such as amino acids and peptides from the soil, although in natural environments, these organic compounds usually occur in lower amounts than nitrate and ammonium [5]. Glutamine is the first organic nitrogen compound derived from the assimilation of ammonium. Regardless of its origin, glutamine is one of the most abundant free amino acids in plants. In addition to protein and nucleotide biosynthesis, glutamine is a major amino donor for synthesis of amino acids and other nitrogen-containing compounds in plants [6]. 
Besides its role in nutrition and metabolism, glutamine also functions as a signaling molecule in the other organisms, including bacteria, yeast, and humans. In bacteria, the signaling role of glutamine is mainly related to metabolic regulation [7]. In enteric bacteria, glutamine synthetase $(\mathrm{G} \ln \mathrm{A})$ is the primary enzyme involved in ammonium assimilation, which is tightly regulated at the transcriptional and posttranscriptional levels by the intracellular nitrogen status. The PII signal transduction protein $G \operatorname{lnB}$, although not a direct sensor of glutamine, senses oxoglutarate and is tightly coupled to glutamine signaling [8]. The PII-modifying enzyme GlnD functions as the primary sensor of glutamine and uridylylates and deuridylylates PII in response to glutamine and oxoglutarate [9]. The PII-GlnD system has been conserved as the central control unit in nitrogen metabolism and glutamine signaling in bacteria [7].

PII homologs also exist in plants [10]. However, there is no evidence to show that plant PII-like proteins are modified by uridylylation, and GlnD homologs have yet to be identified in plants. Bacterial GlnD proteins contain two C-terminal ACT domains (named after aspartate kinase, chorismate mutase and TyrA) that are involved in sensing glutamine (9). Arabidopsis ACR proteins contain ACT domain repeats that have sequence similarity to the C-terminal region of bacterial $\mathrm{GlnD}$, but the functions of these proteins are still unknown $[11,12]$. It has been shown that the PII signal transduction protein is an ATPase and its activity is regulated by oxoglutarate [13]. A more recent study indicated that PII functions in glutamine sensing in many plants [14]. The plant-specific C-terminal extension of PII forms a low-affinity glutamine-binding site that is involved in the regulation of $\mathrm{N}$-acetyl-glutamate kinase (NAGK) activity leading to the formation of arginine and polyamine in the chloroplast [14]. If plants have adapted the conserved PII-GlnD system in glutamine metabolism and signaling, it must have evolved into a form that significantly differs from that of bacteria [15].

In humans, glutamine is the most abundant free amino acid, present at estimated concentrations of $2-20 \mathrm{mM}$ in different cells or tissues [16]. In addition to serving as a metabolic fuel and protein precursor, glutamine also regulates the expression of genes related to metabolism, cell defense, and signal transduction in humans $[16,17]$. The molecular mechanisms involved in the control of gene expression by glutamine are still unclear. Nonetheless, increasing evidence suggests that glutamine may enhance many cell functions via the activation of various transcription factors in mammals and activation of these transcription factors may amplify glutamine signaling $[16,17]$. The target of rapamycin complex 1 (TORC1) is an evolutionarily conserved master regulator of protein translation and cell growth [18]. The yeast TORC1 signaling pathway responds to intracellular levels of glutamine [19]. Glutamine also activates the mammalian TORC1 (mTORC1) to coordinate cell growth and proliferation [20]. These studies highlight the importance of glutamine as a signaling molecule in humans and yeast.

The regulatory and signaling functions of glutamine in plants remain to be explored and most studies on glutamine in plants have focused on its role as the primary amino acid derived from the assimilation of inorganic nitrogen $[21,22]$. For instance, glutamine affects the uptake of nitrate and ammonium, and the activity of nitrate reductase [23-28]. In plants, glutamine also regulates the expression of nitrate reductase, nitrate transporter, and ammonium transporter genes [29-32]. Moreover, glutamine affects the expression of NADH-GOGAT1 in rice [33], as well as the asparagine synthetase $A S N 1$ and the glutamine synthetase GLN1 in Arabidopsis [34, 35]. In addition to feedback regulation, glutamine has been proposed to play a role in nitrogen signaling responsible for the regulation of nitrate uptake [31, 32]. Recent work showed that glutamine plays a crucial role in salicylic acid-associated redox status and disease resistance in Arabidopsis [36]. In rice, glutamine has been implicated in the regulation of nitrogen and cytokinin biosynthesis [37].

As one of the major forms of nitrogen in rice [38], glutamine may have functions that go beyond that of a metabolic fuel or precursor for protein synthesis. Here, we demonstrate that glutamine can effectively support the growth of rice seedlings at a relatively low concentration. To test whether glutamine functions as a signaling molecule in plants, we used transcriptome analysis to identify genes that are rapidly regulated by glutamine in rice roots.

\section{Methods}

\section{Plant material and growth conditions}

Rice (Oryza sativa L. ssp. japonica cv. TNG67) was used in all experiments. For growth analysis, seeds were germinated in darkness at $30^{\circ} \mathrm{C}$ for 3 days and then transferred to hydroponic solutions [39] consisting of modified nitro-

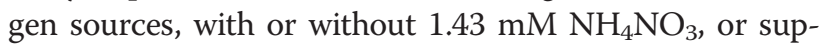
plemented with 0.1 to $10 \mathrm{mM}$ glutamine, and grown under controlled conditions $\left(30{ }^{\circ} \mathrm{C}, 12\right.$-h photoperiod, $200 \mu \mathrm{mol}$ photons $\mathrm{m}^{-2} \mathrm{~s}^{-1}, 70 \%$ relative humidity) for 2 weeks. The hydroponic solution was renewed every 3 days in all experiments.

\section{Determination of chlorophyll content}

Leaves from 17-day-old rice seedlings grown in hydroponic solutions with $1.43 \mathrm{mM} \mathrm{NH} \mathrm{NH}_{4} \mathrm{NO}_{3}(+\mathrm{N})$, without nitrogen $(-\mathrm{N})$ or with 0.1 to $10 \mathrm{mM}$ glutamine were used for determination of chlorophyll content with a Chlorophyll Content Meter (CCM-300, Opti-sciences, NH, USA). 


\section{RNA isolation and microarray analysis}

For microarray analysis, 17-day-old rice seedlings grown in hydroponic solution without $\mathrm{NH}_{4} \mathrm{NO}_{3}(-\mathrm{N})$ were transferred to fresh $-\mathrm{N}$ solution or $-\mathrm{N}$ solution supplemented with $2.5 \mathrm{mM}$ glutamine (+ Gln) for $30 \mathrm{~min}$. Roots and shoots were harvested separately for total RNA isolation using phenol extraction, as previously described [40]. RNA samples from two biological repeats were sent to the Affymetrix Gene Expression Service Lab at Academia Sinica, Taipei, Taiwan (http://ipmb.sini ca.edu.tw/affy/) for target preparation, and hybridization to the GeneChip Rice Genome Array (Affymetrix, Santa Clara, CA, USA). The standard washes and doublestaining were performed on the Affymetrix GeneChip Fluidics Station 450, and the arrays were scanned on the Affymetrix GeneChip Scanner 3000. The scanned arrays were analyzed by Affymetrix GCOS version 1.4 and the raw data were saved as CEL files. The GeneSpring GX 11.5 software was used to analyze the microarray data. Unpaired $t$-tests were performed to examine the reproducibility of the data. Two-fold cutoff and a $P$-value less than 0.05 were applied to select for up- and downregulated genes after $2.5 \mathrm{mM}$ Gln treatment for $30 \mathrm{~min}$. These microarray gene expression data have been deposited in the GEO repository (accession number: GSE56770).

\section{RT-PCR analysis of glutamine-responsive genes}

Seventeen-day-old rice seedlings grown in $-\mathrm{N}$ hydroponic solution were transferred to solutions containing $2.5 \mathrm{mM}$ glutamine for $0,15,30 \mathrm{~min}, 1,4$, and $24 \mathrm{~h}$. Total RNA extracted from Gln-treated roots was used for RTPCR analysis of the glutamine-responsive genes identified by microarray. The RNA samples were digested with DNase I, and reverse transcription was performed with Superscript III RT (Invitrogen, Carlsbad, CA) according to the manufacturer's instructions. The oligo $(\mathrm{dT})_{20}$ primer was used in reverse transcription to synthesize the first strand cDNA. Taq DNA polymerase and PCR kits were purchased from Roche Diagnostics (Indianapolis, IN). The total volume of a single PCR amplification was $50 \mu \mathrm{l}$. For gel electrophoresis, $10 \mu \mathrm{l}$ of the PCR product was loaded on a $1 \%$ agarose gel. Primers used for cDNA amplification of the 35 glutamine-responsive genes and the control gene EF1 $\alpha$ are listed in Additional file 1: Table S1.

\section{Quantitative RT-PCR analysis of glutamine-responsive transcription factor genes}

Seventeen-day-old rice seedlings grown in $-\mathrm{N}$ hydroponic solution were subsequently transferred to solutions containing $2.5 \mathrm{mM}$ glutamine, glutamate, or $1.43 \mathrm{mM} \mathrm{NH}_{4} \mathrm{NO}_{3}$ for $0,15,30 \mathrm{~min}, 1,4$, and $24 \mathrm{~h}$. Total RNA extracted from roots was digested with DNase I and used for quantitative RT-PCR analysis. The sequences of the primers used for quantitative RT-PCR analysis of glutamine-responsive transcription factor genes are listed in Additional file 1: Table S2. All of the quantifications were normalized to the nuclear gene UBC3 (Os02g0634800). The quantitative RT-PCRs were performed in triplicate for each sample in three independent experiments.

\section{Amino acid analysis}

Seventeen-day-old rice seedlings grown in hydroponic solution without $\mathrm{NH}_{4} \mathrm{NO}_{3}(-\mathrm{N})$ were transferred to fresh $-\mathrm{N}$ or $-\mathrm{N}$ supplemented with $2.5 \mathrm{mM}$ glutamine $(+\mathrm{Gln})$ for $30 \mathrm{~min}$ or the indicated time. Roots and shoots were harvested separately for extraction of free amino acids. Amino acids were extracted with $50 \%(v / v)$ methanol: $\mathrm{H}_{2} \mathrm{O}$ solution spiked with internal standard $50 \mu \mathrm{M}$ Norvaline as described [41]. Free amino acids were derivatized with the AccQ•Tag Ultra derivatization kit (Waters, Milford, MA, USA); for derivatization, $10 \mu \mathrm{L}$ of rice extract was mixed with $70 \mu \mathrm{L}$ of AccQ $\cdot$ Tag Ultra borate buffer and $20 \mu \mathrm{L}$ of AccQ $\cdot$ Tag Ultra reagent, followed by incubation for $15 \mathrm{~min}$ at $55{ }^{\circ} \mathrm{C}$. Liquid chromatography of the derivatized amino acids was performed on the Waters Acquity UPLC system equipped with a Waters AccQ $\cdot$ Tag Ultra column $(2.1 \times 10 \mathrm{~mm}$, $1.7 \mu \mathrm{m}$ particles). The separation gradient used was: 0 $0.54 \mathrm{~min}(99.9 \% \mathrm{~A}), 5.0 \mathrm{~min}(90.9 \% \mathrm{~A}), 8.50 \mathrm{~min}$ $(78.8 \% \mathrm{~A}), 8.90-9.50 \mathrm{~min}(40.4 \% \mathrm{~A}), 9.60-10.10 \mathrm{~min}$ $(99.9 \%$ A). The eluent A was $10 \%$ AccQ. Tag Ultra concentrate solvent A, eluent B was $100 \%$ acetonitrile. The mobile phase flow rate was $0.7 \mathrm{~mL} / \mathrm{min}$, and the sample injection volume was $1 \mu \mathrm{L}$. The results shown in Fig. 2 and Table 2 were derived from four biological repeats.

\section{Results}

Glutamine is an effective nitrogen source for plant growth In primary nitrogen assimilation, inorganic nitrogen such as nitrate or ammonium is converted into glutamine and glutamate in plants. However, this is not the only route that plants can use to acquire nitrogen from the environment. Plants can also directly take up amino acids to support their growth and development. We used hydroponic solutions to examine the effects of glutamine as the sole nitrogen source on the growth of rice seedlings (Fig. 1). Compared with seedlings grown in the absence of nitrogen, the addition of $0.1 \mathrm{mM}$ glutamine significantly improved the growth of rice seedlings (Fig. 1a-c). However, the chlorophyll content was low in these seedlings, indicating that rice seedlings grown in $0.1 \mathrm{mM}$ glutamine were still nitrogen deficient (Fig. 1d). When rice seedlings were grown in $0.5 \mathrm{mM}$ glutamine, the length of shoots and roots, and the chlorophyll content were comparable to those grown in $1.43 \mathrm{mM}$ $\mathrm{NH}_{4} \mathrm{NO}_{3}$ (Fig. 1b-d). However, the addition of 1, 2.5, 5, 


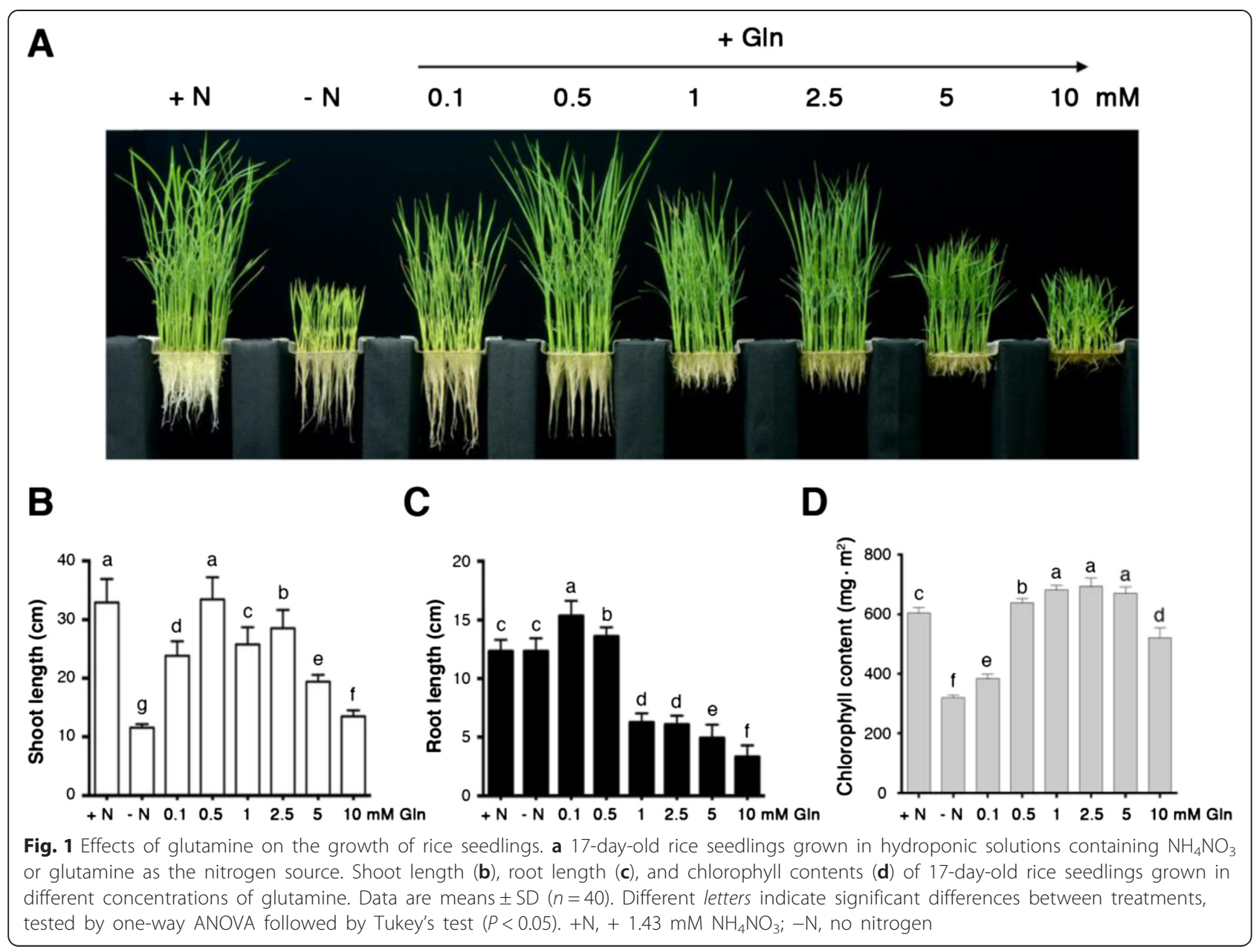

or $10 \mathrm{mM}$ glutamine in the hydroponic solution inhibited the growth of rice seedlings (Fig. 1a-c) and the growth of roots was more sensitive to glutamine inhibition, compared with the growth of shoots. Although the growth of rice seedlings was inhibited by 1, 2.5 and $5 \mathrm{mM}$ glutamine, the chlorophyll content in these seedlings was similar to that of seedlings grown in $1.43 \mathrm{mM}$ $\mathrm{NH}_{4} \mathrm{NO}_{3}$ (Fig. 1d). These results indicated that the inhibitory effects of 1-10 $\mathrm{mM}$ glutamine on the growth of rice seedlings were not due to nitrogen deficiency. Similarly, other amino acids such as alanine and glycine could also serve as efficient nitrogen sources for rice seedlings when supplemented in optimal concentrations in the hydroponic system (Additional file 1: Figure S1). These results are consistent with the notion that plants have the capacity to take up amino acids as nitrogen sources [5].

\section{Nitrogen-starved rice seedlings can rapidly take up glutamine}

In addition to long-term treatments, we also examined if nitrogen-starved rice seedlings could effectively take up glutamine. Seventeen-day-old nitrogen-starved rice seedlings were transferred to hydroponic solutions containing $2.5 \mathrm{mM}$ glutamine for $0-24 \mathrm{~h}$. We then measured the amount of glutamine left in the hydroponic solution during the time course of glutamine treatment. The amount of glutamine in the medium decreased rapidly after $0.25-4 \mathrm{~h}$, and was almost exhausted after $24 \mathrm{~h}$ of treatment (Fig. 2a). These results suggested that the rice seedlings could effectively consume glutamine in the hydroponic solution. We further analyzed the levels of free amino acids in the roots during the time course of glutamine treatment. Compared with the nitrogenstarved seedlings, in the glutamine-treated plants, the levels of glutamine, glutamate, alanine, aspartate, and asparagine increased significantly after $24 \mathrm{~h}$ of glutamine treatment (Fig. 2b-f). The amount of glutamine increased $\sim 10$-fold after $0.25-1 \mathrm{~h}, \sim 30$-fold after $4 \mathrm{~h}$, and continued to increase to $\sim 40$-fold of control levels after $24 \mathrm{~h}$ of glutamine treatment (Fig. 2b).

Feeding of glutamine to nitrogen-starved rice seedlings did not significantly increase the amount of glutamate 


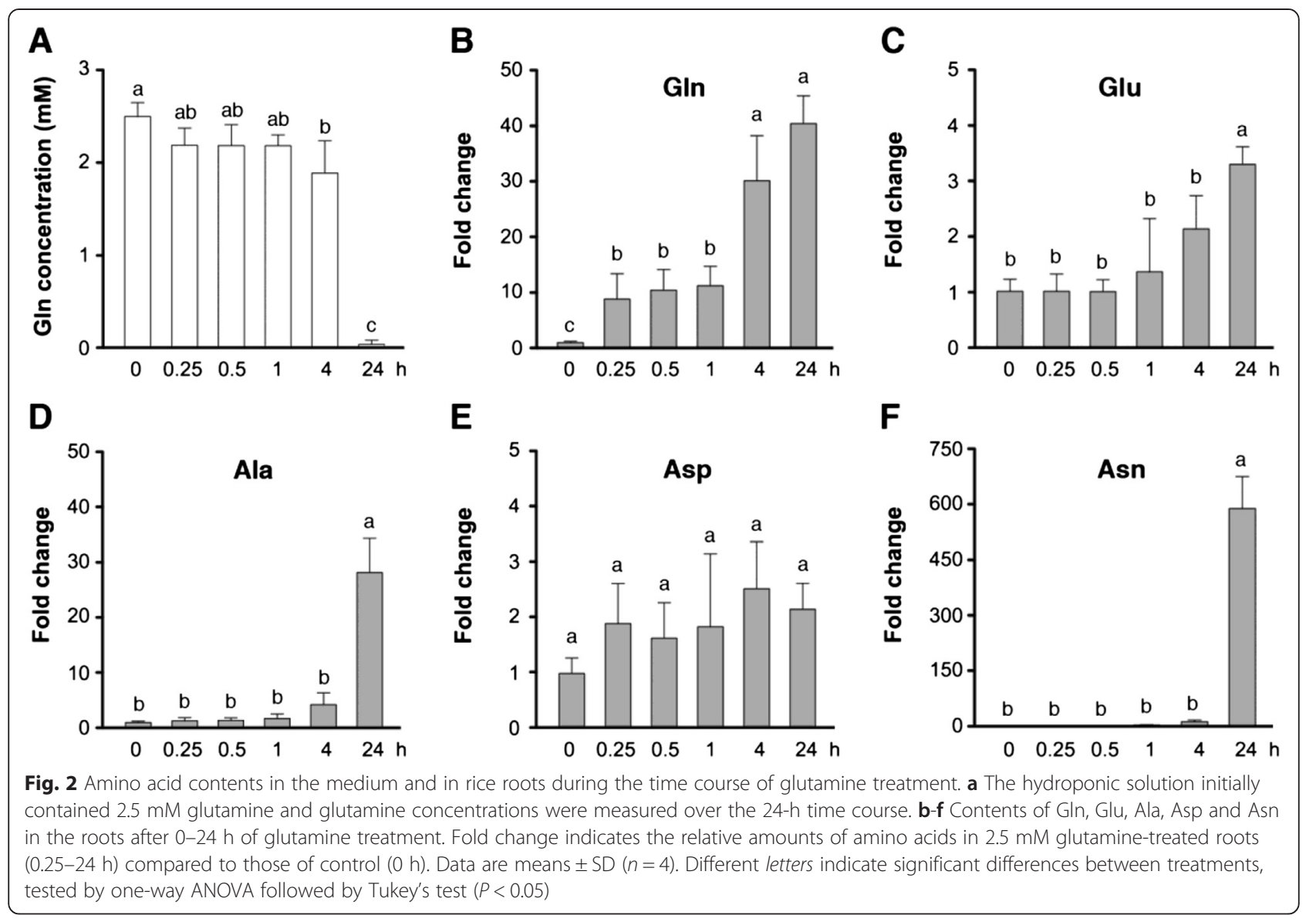

within the first hour, but the levels of glutamate in the roots increased to about 2- to 3-fold of control levels after $4-24 \mathrm{~h}$ of glutamine treatment (Fig. 2c). Alanine levels increased slightly during the first $4 \mathrm{~h}$, and then increased dramatically to about 30-fold of control after $24 \mathrm{~h}$ of glutamine treatment (Fig. 2d). By contrast, the amount of aspartate increased to $\sim 1.5-2.5$-fold of control levels during the glutamine treatment but the differences were not statistically significant (Fig. 2e). Asparagine levels were low in nitrogen-starved seedlings, and feeding of glutamine for $0.25-1 \mathrm{~h}$ did not increase the amount of asparagine in the roots. However, the amount of asparagine dramatically increased to about 600 -fold of control levels after 24 h of glutamine treatment (Fig. 2f).

\section{Transcriptome analysis of early glutamine-responsive genes in rice roots}

In addition to metabolic and nutritional effects, we suspected that glutamine might function as a signaling molecule to rapidly regulate gene expression in rice. To examine this, we treated rice seedlings with $2.5 \mathrm{mM}$ glutamine for $30 \mathrm{~min}$ and used microarray analysis to identify genes that were rapidly induced by glutamine. We used $2.5 \mathrm{mM}$ glutamine, a concentration comparable to the concentration of inorganic nitrogen $\left(1.43 \mathrm{mM} \mathrm{NO}_{3}^{-}\right.$ and $1.43 \mathrm{mM} \mathrm{NH}_{4}^{+}$) commonly used in hydroponic solution [39]. In roots, 41 genes (2-fold cutoff), including 39 up- and 2 down-regulated by glutamine, were identified in the microarray analysis. However, we were unable to verify the up-regulation of 4 genes (Os06g0598500, +2.1fold; Os06g0257600, +2.1-fold; Os05g0427800, +2.2-fold; mitochondrial rps1, +2.6 -fold), and the down-regulation of 2 genes (Os04g0607500, -2.3-fold; Os06g0695500, -2.4fold) by RT-PCR (data not shown). Thus, we concluded that glutamine rapidly upregulated the expression of at least 35 genes in rice roots (Table 1). The functions of these genes are related to metabolism, transport, signal transduction, and stress responses.

Interestingly, 10 of the 35 early glutamine-responsive genes encode putative transcription factors, including two LBD37-like proteins, Os03g0445700 and Os07g0589000 (Table 1). Arabidopsis LBD/37/38/39 transcription factors are involved in the regulation of nitrogen responses [42]. Rice has two LBD37-like proteins, Os03g0445700 and Os07g0589000 (http://www.ncbi.nlm.nih.gov/homologene/ ?term=Arabidopsis\%20LBD37), which share $72 \%$ amino acid sequence similarity to each other (Additional file 1: 
Table 1 Glutamine-responsive genes in rice roots

\begin{tabular}{|c|c|c|c|}
\hline Locus ID & Accession no. & Fold change $(+\mathrm{Gln} /-\mathrm{N})$ & Gene description \\
\hline Os05g0114400 & NM_001060995 & 5.4 & ZOS5-02, $\mathrm{C} 2 \mathrm{H} 2$ zinc finger protein \\
\hline Os09g0522200 & NM_001070247 & 4.0 & DREB1A, dehydration-responsive element-binding protein $1 \mathrm{~A}$ \\
\hline Os11g0184900 & NM_001072451 & 4.0 & NAC5, no apical meristem protein 5 \\
\hline Os03g0236200 & NM_001056025 & 3.6 & GAD3, glutamate decarboxylase 3 \\
\hline Os06g0633100 & NM_001064664 & 3.6 & GDU-like, glutamine dumper-like \\
\hline Os03g0823400 & NM_001058277 & 3.5 & BBTI13, Bowman-Birk type bran trypsin inhibitor 13 \\
\hline Os09g0482800 & NM_001188974 & 3.2 & EF hand family protein \\
\hline Os01g0952900 & NM_001051958 & 3.1 & IRO2, helix-loop-helix DNA-binding domain containing protein \\
\hline Os08g0386200 & NM_001068242 & 3.0 & WRKY69 \\
\hline Os05g0545300 & NM_001062746 & 2.8 & MAPKKK57 \\
\hline Os04g0673300 & NM_001060766 & 2.8 & RR6, type-A response regulator 6 \\
\hline Os08g0172900 & N.A. & 2.8 & Unknown protein \\
\hline Os03g0445700 & NM_001057003 & 2.7 & LBD37-like \\
\hline Os08g0138100 & N.A. & 2.7 & Uclacyanin 1 (UCC1)-like \\
\hline Os07g0410300 & NM_001188228 & 2.6 & AP2/ERF106, AP2 domain containing protein \\
\hline Os02g0687200 & NM_001054310 & 2.6 & DUF581, domain of unknown function 581 \\
\hline Os07g0119300 & NM_001065305 & 2.6 & MYB-like family transcription factor \\
\hline Os03g0564600 & NM_001057032 & 2.6 & RLK-like \\
\hline Os05g0194900 & NM_001061394 & 2.4 & PFK04, phosphofructokinase 04 \\
\hline Os01g0975000 & NM_001052095 & 2.4 & DUF966, domain of unknown function 966 \\
\hline Os02g0532900 & NM_001053562 & 2.4 & GH17, glycosyl hydrolases family 17 \\
\hline Os05g0402900 & NM_001062031 & 2.4 & EDGP-like, xylanase inhibitor \\
\hline Os01g0699100 & NM_001050512 & 2.3 & MAPKKK63 \\
\hline Os07g0589000 & NM_001066683 & 2.3 & LBD37-like \\
\hline Os12g0113500 & NM_001072509 & 2.3 & CIPK14, calcineurin B-like interacting protein kinase 14 \\
\hline Os02g0585100 & NM_001053799 & 2.3 & Heavy metal associated (HMA) domain containing protein \\
\hline Os08g0138200 & NM_001067493 & 2.2 & Uclacyanin 1 (UCC1)-like \\
\hline Os04g0301500 & NM_001058941 & 2.2 & bHLH, basic helix-loop-helix family protein \\
\hline Os02g0205500 & NM_001052785 & 2.2 & KCS11, 3-ketoacyl-CoA synthase 11 \\
\hline Os03g0187800 & NM_001055748 & 2.2 & PUP3-like, purine permease 3-like \\
\hline Os02g0807900 & NM_001054992 & 2.1 & WAK21, cell wall associated kinase 21 \\
\hline Os04g0194500 & NM_001058746 & 2.1 & $\mathrm{ABC}$ transporter \\
\hline Os01g0845000 & NM_001185719 & 2.0 & DUF668, domain of unknown function 668 \\
\hline Os08g0446800 & NM_001068463 & 2.0 & GDU-like, glutamine dumper-like \\
\hline Os03g0124800 & NC_008396 & 2.0 & Unknown protein \\
\hline
\end{tabular}

Total RNA extracted from 17-day-old rice seedlings grown in hydroponic solution without nitrogen (-N) or treated with 2.5 mM glutamine for 30 min (+ Gln) was used for microarray analysis. The results were derived from two biological replicates. Os08g0172900 and Os08g0138100 were annotated in the RIKEN BASE (https://database.riken.jp/sw/en/RIKENBASE/rib158i/) but not available (N.A.) in National Center for Biotechnology Information (http://www.ncbi.nlm.nih.gov/)

Figure S2). Although the exact functions of rice LBD37-like proteins are still unknown, the LBD37-like proteins, Os03g0445700, has been shown to be associated with nitrogen metabolism in rice [43]. The other glutamineresponsive transcription factor genes are: ZOS5-2 (OsO5 g0114400), a C2H2 zinc finger protein [44]; DREB1A (Os09g0522200), dehydration-responsive element-binding protein 1A involved in cold signaling [45]; NAC5 (Os1 1g0184900), no apical meristem protein 5 involved in abiotic stress responses [46-48]; IRO2 (Os01g0952900), a helix-loop-helix DNA-binding domain containing protein involved in iron uptake under iron deficiency [49-51] and GA3 responses [52]; WRKY69 (Os08g0386200), a WRKY domain-containing protein; AP2/ERF106 (Os07g0410300), 
an AP2/ERF domain-containing protein [53]; MYB-like (Os07g0119300), a MYB-like family protein; and bHLH (Os04g0301500), a basic helix-loop-helix family protein.

In addition to transcription factor genes, the early glutamine-responsive genes included several genes encoding proteins involved in various signaling pathways. The calcineurin B-like interacting protein kinase 14 (CIPK14, Os12g0113500) is involved in the regulation of defense and stress signaling [54, 55]. The RR6 (Os04g0673300) gene encodes a type-A response regulator that is involved in cytokinin signaling pathways [56, 57]. The Os09g0482800 gene encodes a putative calcium-binding EF-hand family protein. The expression of some kinase genes, including MAPKKK57 (Os05g0545300), MAPKKK63 (Os01g0699 100) [58], RLK-like (receptor-like kinase, Os03g0564600), and WAK21 (cell wall-associate kinase 21, Os02g0807900) [59] was also rapidly induced by glutamine (Table 1 ).

Among the early glutamine-responsive genes, GAD3 (glutamate decarboxylase 3), two glutamine dumper (GDU)-like genes (Os06g0633100 and Os08g0446800), PFK04 (phosphofructokinase 04), glycosyl hydrolase family 17 (GH17, Os02g0532900), KCS11 (3-ketoacyl-CoA synthase 11, Os02g0205500), PUP3-like (purine permease 3-like, Os03g0187800), and an $\mathrm{ABC}$ transporter gene Os04g0194500 are involved in metabolism or transport. The expression of several stress response-related genes including Bowman-Birk type bran trypsin inhibitor 13 (BBTI13, Os03g0823400), uclacyanin 1 (UCC1)-like genes (Os08g0138100 and Os08g0138200) encoding plastocyanin-like domain containing proteins, $\mathrm{Os} 05 \mathrm{~g}$ 0402900 encoding an extracellular dermal glycoprotein (EDGP)-like protein or xylanase inhibitor, and $\mathrm{OsO} g$ 0585100 encoding a heavy metal associated (HMA) domain containing protein, and several unknown function genes (Os01g0845000, Os01g0975000, Os02g068 7200, Os03g0124800, and Os08g0172900) was also rapidly induced by glutamine (Table 1).

In contrast to roots, our microarray analysis did not identify any early glutamine-responsive genes in shoots (2-fold cutoff, data not shown). This is consistent with our finding that the glutamine levels did not change significantly in shoots after $30 \mathrm{~min}$ of glutamine treatment (Table 2). Analysis of free amino acids in glutaminetreated $(2.5 \mathrm{mM}, 30 \mathrm{~min})$ samples revealed that the endogenous levels of glutamine increased dramatically ( 11.6-fold) in roots but not in shoots as compared with those in nitrogen-starved rice seedlings (Table 2).

\section{Verification of the microarray data by RT-PCR}

To independently verify the microarray data, we used RT-PCR to examine the effects of glutamine treatments $(2.5 \mathrm{mM}, 15 \mathrm{~min}$ to $24 \mathrm{~h}$ ) on the expression of all 35 early glutamine-responsive genes in the rice roots. Interestingly, most of the glutamine-responsive genes were rapidly induced by glutamine, increasing within $15 \mathrm{~min}$ (Fig. 3). The expression of two LBD37-like genes and ZOS5-02 was rapidly induced by glutamine and remained at high levels after 4 to $24 \mathrm{~h}$ (Fig. 3a). By contrast, the expression of DREB1A, WRKY69, bHLH, MYB-like, and IRO2 was rapidly induced by glutamine, peaked between 15 and $60 \mathrm{~min}$, and decreased to levels comparable to those of control after 4 to $24 \mathrm{~h}$ (Fig. 3a). Steady-state levels of AP2/ERF106 transcripts increased rapidly and transiently after $15-30 \mathrm{~min}$ of glutamine treatment, whereas the expression of NAC5 was rapidly induced and stayed at high levels during the time course of glutamine treatment (Fig. 3a). The expression of EF1 $\alpha$ in the same samples was analyzed by RT-PCR as a control (Fig. 3a).

In addition to transcription factor genes, glutamine also rapidly induced the expression of several kinase and regulatory genes. The expression of MAPKKK57 and WAK21 was transiently induced by glutamine and peaked at 15 and $30 \mathrm{~min}$, respectively (Fig. $3 \mathrm{~b}$ ). The expression of MAPKKK63, RR6, and RLK-like was rapidly induced by glutamine, peaked at $15-60 \mathrm{~min}$, and decreased to levels comparable to those of control after 424 h (Fig. 3b). By contrast, steady-state levels of CIPK14 transcripts increased rapidly and continued to accumulate to higher levels during the time course of glutamine treatment (Fig. 3b). Similarly, the expression of EF-hand (Os09g0482800) was rapidly and strongly induced by glutamine after 15-30 min and remained at high levels after 1-24 h (Fig. 3b).

For metabolic and transporter genes, the expression of GAD3, PUP3-like, KCS11, and GH17 was rapidly induced by glutamine, peaked at $15-60 \mathrm{~min}$, and decreased to levels comparable to those of control after 4-24 h (Fig. 3c). By contrast, the expression of PFK04 and an $\mathrm{ABC}$ transporter gene Os04g0194500 was continuously induced by glutamine during the time course of glutamine treatment (Fig. 3c). The expression of two $G D U$-like genes was rapidly and transiently induced by glutamine after treatments for 15-30 min (Fig. 3c).

The expression of stress-responsive gene BBTI13 was rapidly and continuously induced by glutamine (Fig. 3d). By contrast, the expression of HMA and a UCC1-like (Os08g0138100) gene was only transiently induced by glutamine after 15-30 min (Fig. 3d). The expression of another UCC1-like gene (Os08g0138200) and a stress-responsive EDGP-like gene was induced by glutamine after $15 \min -4 \mathrm{~h}$ and decreased to levels comparable to those of control after $24 \mathrm{~h}$ (Fig. 3d). The expression of several unknown function genes, including DUF581, DUF668, DUF966, Os03g0124800, and $O s 08 g 0172900$, was rapidly induced by glutamine, peaked at 15-30 min, and gradually decreased to levels comparable to those of control after 4-24 $\mathrm{h}$ (Fig. 3d). 
Table 2 Amino acid contents (nmole/g FW) of 17-day-old rice seedlings

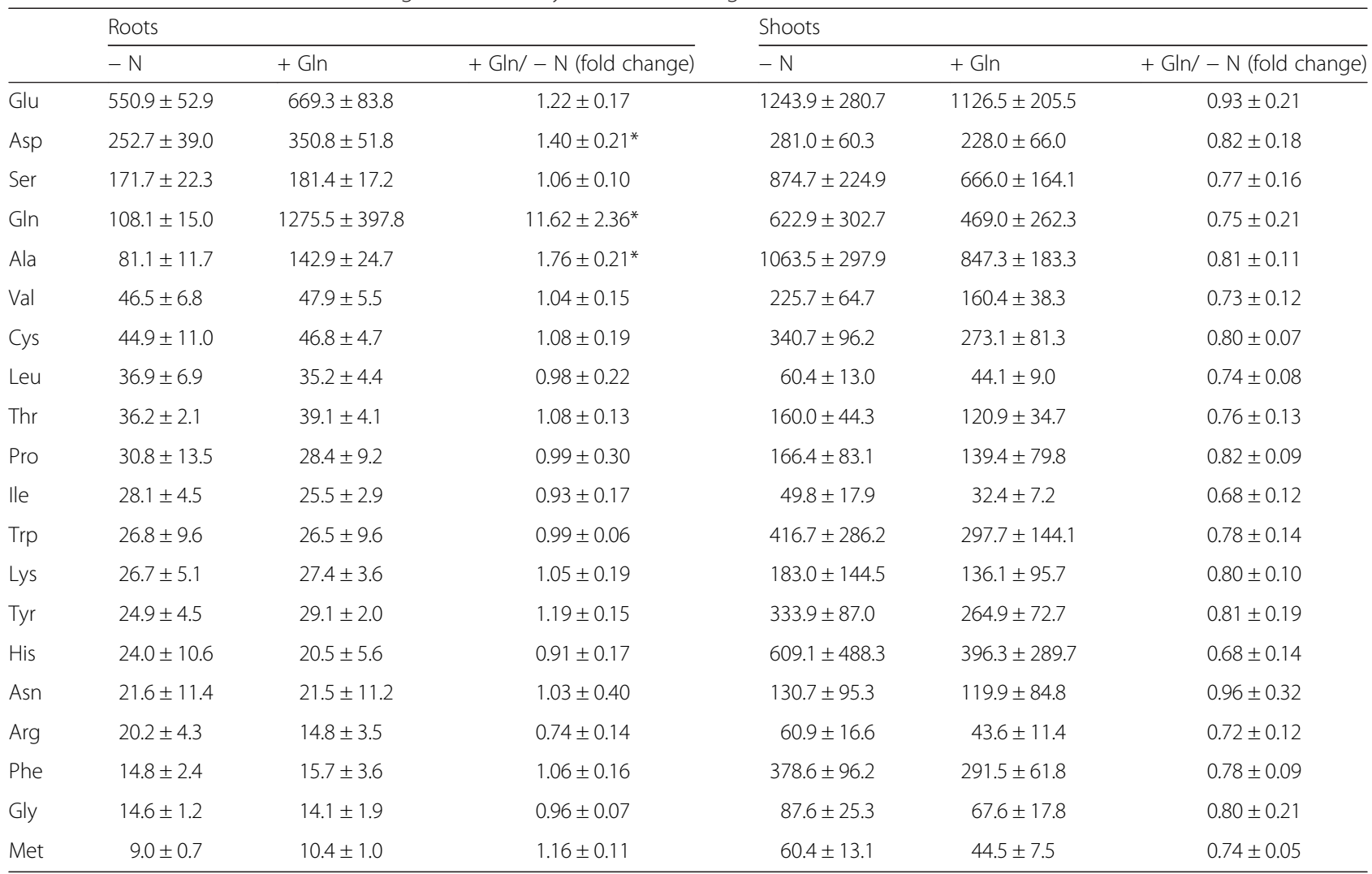

$-N$ without nitrogen, + Gln treated with $2.5 \mathrm{mM}$ glutamine for $30 \mathrm{~min}$. Results were derived from four biological replicates. ${ }^{*}$ indicates $p<0.05$ after analysis with Student's $t$-test

\section{Effects of glutamate and ammonium nitrate on the expression of glutamine-responsive transcription factor genes}

To further examine if the transcriptional response was specific to glutamine, we used quantitative RT-PCR to compare the effects of glutamine, glutamate, and ammonium nitrate on the expression of early glutamineresponsive transcription factor genes. Nitrogen-starved rice seedlings were transferred to hydroponic solutions containing $2.5 \mathrm{mM}$ glutamine, glutamate, or $1.43 \mathrm{mM}$ ammonium nitrate for $15 \mathrm{~min}$ to $24 \mathrm{~h}$. Compared with the expression in nitrogen-starved rice seedlings, the expression of these transcription factor genes was also rapidly induced by glutamate and ammonium nitrate in the roots (Fig. 4). However, the expression patterns and the amount of transcripts accumulated in response to different nitrogen sources varied from gene to gene. Some genes were commonly induced by glutamine, glutamate, and ammonium nitrate to similar extents, whereas some genes were preferentially induced by a specific nitrogen source. For instance, the expression of ZOS5-02 was strongly induced by glutamine and ammonium nitrate ( 180-fold, $30 \mathrm{~min}$; 600-fold, $1 \mathrm{~h}$ ), but induced less strongly by glutamate (38-fold, $30 \mathrm{~min}$; 75-fold, $1 \mathrm{~h}$ ) (Fig. 4a). Although the expression of LBD37-like (Os07g0589000) was induced by glutamate, glutamine, and ammonium nitrate to similar levels after 4 and $24 \mathrm{~h}$, glutamine seemed to have stronger effects than glutamate and ammonium nitrate on the induction of this gene within the first hour (Fig. 4b). Similarly, glutamine had a stronger effect than glutamate and ammonium nitrate on the induction of another LBD37-like gene (Os03g0445700) and $A P 2 / E R F 106$ after treatments for $15 \mathrm{~min}$ (Fig. 4c,d).

By contrast, the expression of $b H L H$ was rapidly and markedly induced by glutamate, which showed a stronger effect than glutamine and ammonium nitrate within the first hour of treatments (Fig. 4e). Similar to bHLH, the expression of $I R O 2$ was rapidly and strongly induced by glutamate within the first hour, whereas the induction by glutamine and ammonium nitrate was relatively mild after treatments for $30 \mathrm{~min}$ to $1 \mathrm{~h}$ (Fig. 4f). While the expression of DREB1A was induced by all nitrogen sources to similar levels after 0.5 to $24 \mathrm{~h}$ of treatments, glutamate, and glutamine seemed to have stronger effects than ammonium nitrate on the initial induction (e.g. $15 \mathrm{~min}$ ) of DREB1A (Fig. 4g). 


\section{A}

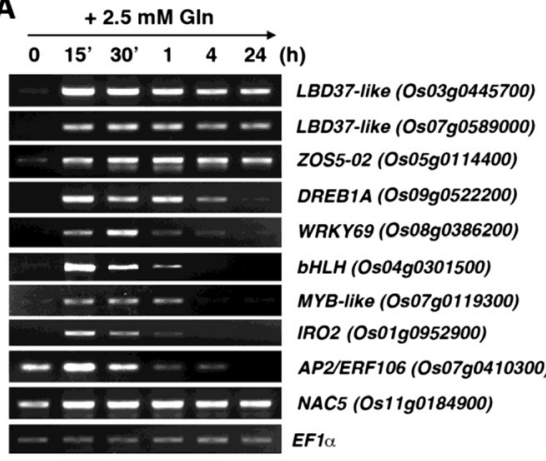

B
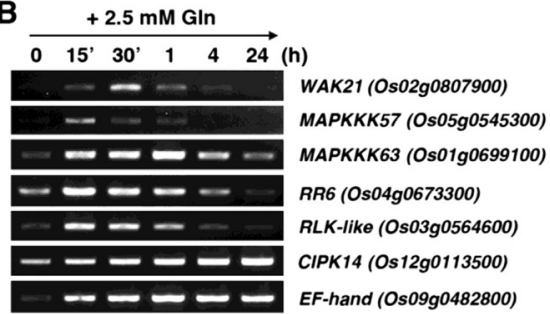

C
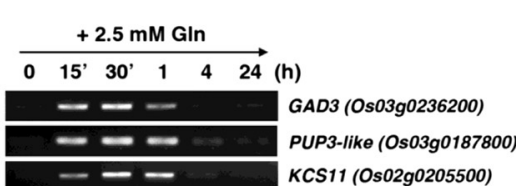

-

- - WH17 (Os02g0532900)

- - . ABC transporter (Os04g0194500)

- - GDU-like (Os06g0633100)

$\ldots-\ldots \ldots$ GDU-like (Os08g0446800)

D
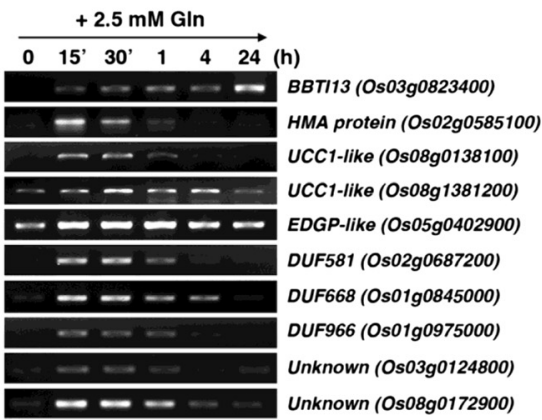

Fig. 3 RT-PCR analyses of glutamine-responsive genes. Total RNA extracted from roots of 17-day-old glutamine-treated rice seedlings was used for RT-PCR analysis to verify the expression of 35 genes identified by microarray analysis. a Transcription factor genes. $\mathbf{b}$ Kinase or signal transducer genes. c Metabolic or transporter genes. d Stress response or unknown function genes. The expression levels of EF1a in the same samples are shown as a control

Although all nitrogen sources could rapidly induce the expression of MYB-like, ammonium nitrate had more pronounced effects than glutamate and glutamine on the induction of MYB-like during the treatments (Fig. 4h). Similarly, the expression of NAC5 and WRKY69 was induced by all nitrogen sources. Nevertheless, ammonium nitrate had stronger effects on the induction of these genes than glutamate and glutamine after $1 \mathrm{~h}$ of treatment (Fig. 4i,j).

\section{Discussion}

\section{Glutamine plays a critical role in plant nutrition} and metabolism

Glutamine may enter the plant cell through amino acid transporters and can serve as a critical nitrogen source for plant growth and development. We demonstrated that rice could effectively use glutamine as a nitrogen source at a concentration significantly lower than that of ammonium nitrate. Based on parameters such as root and shoot length, and chlorophyll content, we showed that supplementation of $0.1 \mathrm{mM}$ glutamine could significantly improve rice seedling growth and $0.5 \mathrm{mM}$ glutamine was as effective as $1.43 \mathrm{mM}$ ammonium nitrate (Fig. 1). These results suggest that glutamine is a potential nitrogen source for plants in natural environments. Analysis of amino acid levels after glutamine time course treatment further confirmed that rice could rapidly take up glutamine from hydroponic solution. Interestingly, the sudden increase of glutamine also rapidly induced the expression of two GDU-like genes (Fig. 3). Glutamine dumpers are plant-specific membrane proteins that are involved in nonselective amino acid export [60]. The Arabidopsis GDU1 overexpression lines have enhanced glutamine secretion, reduced amino acid uptake, and increased amino acid contents in leaf apoplasm and xylem sap $[60,61]$. The induction of GDU-like genes by glutamine may promote the allocation of amino acids in the apoplast and xylem sap, which may help the transport of amino acids to nitrogen-starved tissues.

In addition to synthesis of proteins and nucleotides, one of the major routes of glutamine metabolism is the formation of glutamate catalyzed by Fd- or NADH-GOGAT in plants. In glutamine-treated rice roots, some of the excess glutamine may be quickly converted to glutamate. However, the amounts of glutamate did not change significantly during the first $4 \mathrm{~h}$, and only increased slightly after $24 \mathrm{~h}$ of glutamine treatment (Fig. 2c). Glutamate is a very active amino acid that may be rapidly converted to other nitrogen-containing compounds in the cell. For instance, glutamate is the primary nitrogen donor for most transamination reactions in plants [6]. In nitrogen-deficient cells, glutamate may donate its amine group to $\alpha$-keto acids such as pyruvate and oxaloacetate for the synthesis of alanine and aspartate, respectively. In fact, the amounts of alanine and aspartate increased rapidly in glutaminetreated roots (Table 2). 


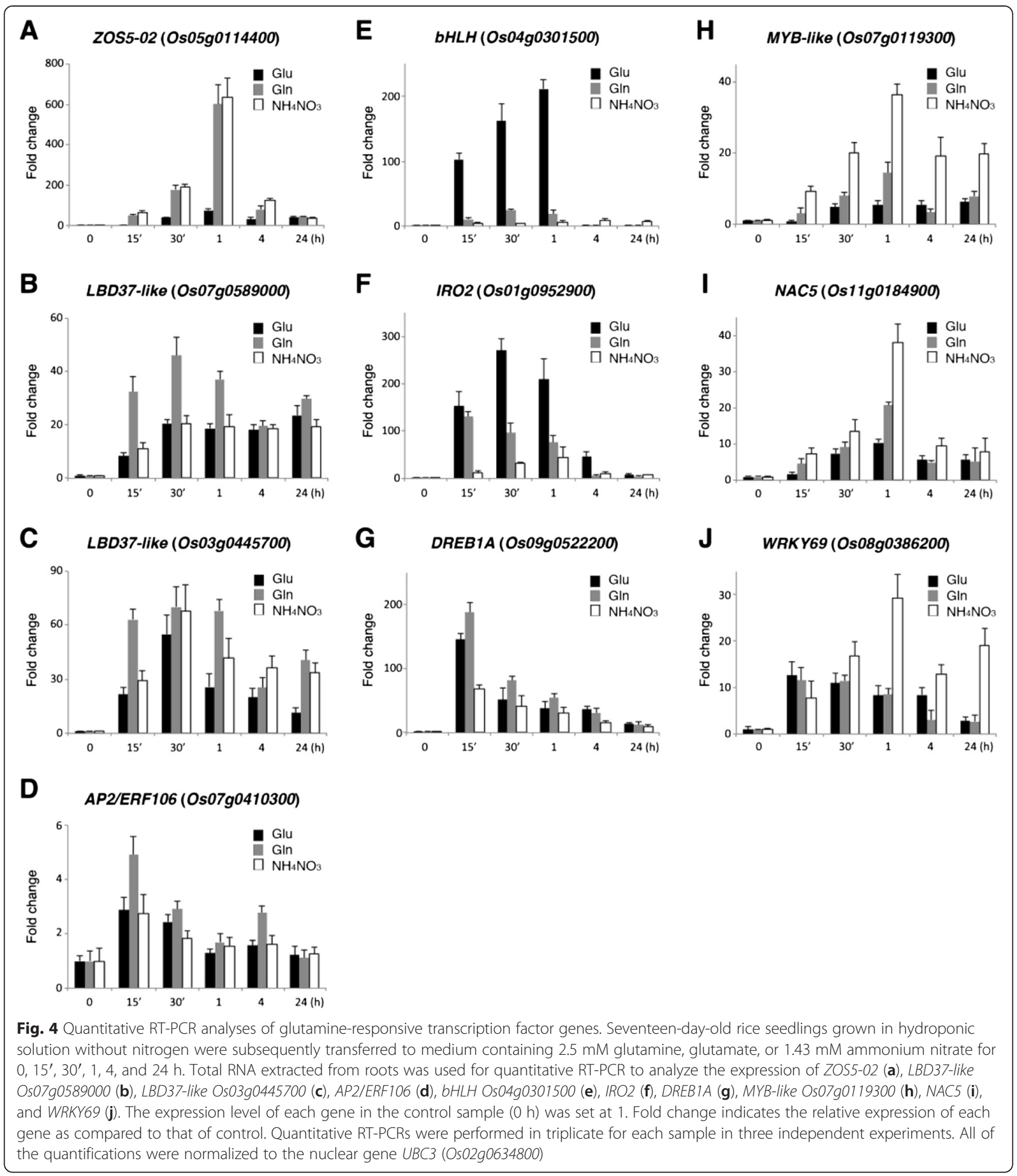

In contrast to glutamate, asparagine is a relatively inert amino acid. Asparagine started to accumulate in glutamine-treated roots after $4 \mathrm{~h}$ and increased dramatically after $24 \mathrm{~h}$. It is possible that the rice seedlings were no longer deficient of nitrogen after $4-24 \mathrm{~h}$ of glutamine treatment. Asparagine and glutamine have higher nitrogen to carbon ratios and usually serve as nitrogen storage or transport compounds in plants. Thus, the plants may have stored excess nitrogen as asparagine and glutamine in $24 \mathrm{~h}$ glutamine-treated 
roots (Fig. 2). By contrast, plant cells have to balance nitrogen metabolism by maintaining the homeostasis of glutamate [6]. So the content of glutamate will not fluctuate dramatically, even in excess-nitrogen conditions.

\section{Glutamine rapidly regulates gene expression in plants} In addition to glutamine's role as a metabolic fuel, increasing evidence has implicated that glutamine sensing and signaling pathways also exist in plants [14]. Besides its well-known effects on the activation of mTORC1 signaling pathways, glutamine also affects the expression of several key transcription factor genes involved in stress responses in humans $[16,17]$. It is intriguing that 10 of the 35 early glutamine-responsive genes identified in this study encode putative transcription factors. Notably, glutamine rapidly induced two LBD37-like genes that regulate nitrogen responses in plants [42, 43] (Fig. 3). In addition, DREB1A, IRO2, and NAC5 encoding transcription factors involved in various stress responses [45-51] are among the early glutamine-responsive genes identified in this study. It is not clear why glutamine activates the expression of these genes. One of the possible explanations is that these stress-related transcription factors also function in the regulation of nitrogen responses in rice. Alternatively, the glutamine signaling pathway may link to a number of cell functions including stress tolerance beyond nitrogen metabolism via the activation of these transcription factors in plants. Of course, further studies are required to explore these possibilities. The functions of the other early glutamine-responsive transcription factor genes, including ZOS5-02, WRKY69, bHLH (Os04g0301500), MYB-like (Os07g0119300), and ERF106 (Os07g0410300), have yet to be characterized. It will be interesting to examine if these putative transcription factors are involved in the interplay of nitrogen and stress signaling pathways in rice.

In addition to transcription factor genes, the expression of several kinase genes, including CIPK14, MAPKKK57, MAPKKK63, WAK21, and RLK-like, which function in various signaling pathways, was also rapidly induced by glutamine. Calcium $\left(\mathrm{Ca}^{2+}\right)$ is a universal second messenger that plays an important role in many signaling pathways in plants. Calcineurin B-like proteins are $\mathrm{Ca}^{2+}$ sensors that specifically interact with CIPKs in plant $\mathrm{Ca}^{2+}$ signaling. Interestingly, glutamine rapidly induced the expression of CIPK14 (Fig. 3), which functions in biotic and abiotic responses $[54,55]$. Similarly, the expression of an EF-hand gene encoding a putative $\mathrm{Ca}^{2+}$-binding protein was also rapidly induced by glutamine (Fig. 3). It is possible that the multifunctional $\mathrm{Ca}^{2+}$ signaling pathways are involved in glutamine sensing and signaling in plants. It will be interesting to examine if CIPK14 also plays a role in integrating nitrogen responses to stress signaling pathways in rice. The functions of MAPKKK57, MAPKKK63,
WAK21, and RLK-like genes have yet to be characterized. Further studies are required to examine if these kinases are involved in glutamine or nitrogen signaling pathways in plants.

The plant hormone cytokinins have been closely linked to nitrogen signaling [62]. Glutamine-related signals are involved in the regulation of cytokinin biosynthesis [37]. Response regulators (RR) act as important components of the cytokinin signaling pathways in Arabidopsis [63]. In addition, transport of cytokinins mediated by purine transporters of the PUP family is involved in long-distance signaling [64]. Interestingly, glutamine rapidly induced the expression of RR6 and PUP3-like genes in rice roots (Fig. 3). These results suggest that glutamine may exert its functions by directly interacting with cytokinin biosynthesis and signaling pathways. It will be interesting to further examine if glutamine can trigger local and long distance cytokinin signaling via the induction of RR6 and PUP3-like genes in rice.

\section{Crosstalk between glutamine and stress signaling pathways in plants}

In addition to DREB1A, IRO2, NAC5, and CIPK14, glutamine also rapidly induced the expression of many stress-related genes, such as EDGP-like, BBTI13, HMA, UCC1-like, KCS11, and GH17 (Fig. 3). These results are reminiscent of the glutamine studies in humans. Glutamine is the most abundant amino acid in humans and its function goes beyond that of a fuel for metabolism or a precursor for protein synthesis [16]. A number of studies reveal that glutamine can regulate the expression of a large variety of target genes involved in major functions including stress responses $[16,17]$. In addition to the regulation of metabolism-related genes, glutamine also induces a diverse array of transcription factor genes involved in inflammatory responses, proliferation, apoptosis, and survival in mammals [16, 17]. Despite its central regulatory role in numerous functions, the underlying molecular mechanisms and most of the signaling pathways remain to be identified. Similarly, glutamine is one of the most abundant amino acid in plants. Besides its role as metabolic fuel and a precursor of proteins, nucleic acids, and amino sugars, glutamine may have additional functions that have yet to be established in plants.

The induction of stress-responsive genes by glutamine raises an interesting question whether glutamine, an important nutrient, also functions as a stress signal in plants. Generally, if the amount of nutrients exceeds the amount required, this excess may inhibit normal growth, development, and metabolism. Consistent with this notion, we have shown that high concentrations of amino acids can inhibit the growth of rice seedlings. When the model plant Arabidopsis was grown on 
medium containing $5 \mathrm{mM}$ glutamine as the sole nitrogen source, the biomass was comparable to that of plants grown on nitrate [65]. By contrast, growth on $1 \mathrm{mM}$ glutamine significantly inhibited root growth in rice (Fig. 1). While the mechanism of this amino acid inhibition is not well understood, rice seems to be more sensitive to glutamine inhibition than Arabidopsis. It is well known that most of the amino acid biosynthetic pathways are regulated by feedback inhibition. It is possible that glutamine in excess may inhibit some enzymes or interfere the absorbance of other nutrients. Thus, the specific growth condition with high concentrations of single amino acids, e.g. glutamine in this study, may cause growth inhibition and trigger the expression of stressresponse genes.

The effects of glutamine on gene expression may occur by a direct effect of glutamine or through products of glutamine metabolism. Although the mechanism by which glutamine affects gene expression is not well understood, the synthesis of glutathione derived from glutamine, and the increase of reactive oxygen species (ROS) after glutamine addition are among the possible mechanisms that mediate the glutamine responses in mammals [16]. It will be interesting to examine if glutamine changes the redox status or affects the production of ROS in plants. Most stress-responsive genes, including DREB1A, IRO2, HMA, UCC1-like, KCS11, and GH17, and many other genes identified in this study, were rapidly and transiently (15-60 $\mathrm{min}$ ) induced by glutamine (Fig. 3). It is possible that the sudden and dramatic increase of endogenous levels of glutamine may affect the cell's redox status and ROS production, which in turn may induce the expression of stress-responsive genes.

Regardless of the underlying molecular mechanisms, the effects of glutamine on the regulation of gene expression suggest that glutamine may interact with stress signaling pathways in plants. While amino acids such as glutamine can serve as nutrients to support plant growth and development, they may also function as stressors to elicit defense responses in plants.

\section{Regulation of glutamine-responsive genes by general nitrogen status}

The expression of most glutamine-responsive transcription factor genes was also rapidly induced by glutamate and ammonium nitrate (Fig. 4). These results suggest that the expression of these genes is not specifically regulated by glutamine. The transition from nitrogen deficiency to nitrogen sufficiency, rather than specific induction by glutamine, may explain the expression patterns of some early glutamine-responsive genes identified in this study. Since the endogenous levels of glutamine continued to increase after 4-24 h of treatment (Fig. 2), it is reasonable to expect that the expression of glutamine-regulated genes would also be maintained at high levels during this time. However, the expression of many glutamine-responsive genes increased significantly within the first hour and then decreased to levels comparable to those of control (Fig. 3). Although this expression pattern does not parallel the endogenous glutamine levels, it is consistent with the notion that the rice seedlings are no longer deficient of nitrogen after 4-24 h of glutamine treatment, as indicated by the dramatic accumulation of asparagine and glutamine (Fig. 2). Thus, signals derived from overall nitrogen deficiency or nitrogen sufficiency, rather than a specific nitrogen source, may play a major role in the regulation of these genes.

In addition to sensing endogenous levels of nitrogen, plants may also have mechanisms to sense the nitrogen status in the environment. For instance, nitrate transporters have been proposed to function as nitrate sensors in plants [66]. It is conceivable that similar sensing mechanism for glutamine or the availability of nitrogen may exist in plants. Rice seedlings may be able to sense the exogenous levels of glutamine or the availability of nitrogen and respond with specific regulation of gene expression. The expression patterns of some glutamineresponsive genes, for instance, those involved in signal transduction including DREB1A, MAPKKK63, RR6 and $R L K$-like, correspond well with the availability of glutamine in the medium. The expression of these genes was induced by glutamine to their highest levels at $15-60 \mathrm{~min}$, was lower at $4 \mathrm{~h}$, and was almost not induced at $24 \mathrm{~h}$ (Fig. 3). Regardless of the specific nitrogen source, the combination of internal nitrogen status (e.g. nitrogen deficiency versus nitrogen sufficiency) and the availability of external nitrogen may contribute to the regulation of early glutamine-responsive genes identified here.

Still, the expression levels of glutamine-responsive transcription factor genes were differentially induced by glutamine, glutamate and ammonium nitrate. For instance, glutamine had stronger effects on the induction of LBD37-like (Os07g0589000) than did glutamate and ammonium nitrate. The expression of $\mathrm{bHLH}$ and IRO2 is preferentially induced by glutamate, whereas ammonium nitrate has stronger effects on the induction of $M Y B$-like and NAC5. It is likely that the general nitrogen status precedes the specificity of nitrogen source in regulating the expression of these transcription factor genes. Thus, the addition of organic (e.g. glutamine or glutamate) or inorganic nitrogen to nitrogen-starved rice seedlings would generally induce the expression of these genes, but the levels of induction were determined by the specific nitrogen source.

\section{Amino acid sensing and signaling in plants}

Amino acids are biochemically diverse molecules that are essential for cell growth. Although glutamine and 
glutamate are closely related in metabolism, they may have distinct effects on the induction of plant gene expression. The expression of ZOS5-02 was rapidly and dramatically induced by glutamine, but only mildly induced by glutamate (Fig. 4). By constrast, the expression of $b H L H$ was rapidly and strongly induced by glutamate, but only mildly induced by glutamine (Fig. 4). These results imply that different amino acids may have some specificity in the regulation of plant gene expression. However, it remains unclear how plants sense specific amino acids. In mammalian cells, mTORC1 is involved in integrating the availability of nutrients and growth factors to regulate cell growth and proliferation. Several amino acids, including glutamine, arginine, and leucine, effectively activate mTORC1, and intensive studies have just begun to uncover the complex machinery of amino acid sensing by mTORC 1 in mammalian cells $[20,67]$. It is not clear if similar regulatory systems exist in plants. The largely unexplored amino acid sensing mechanisms in plants are expected to be at least as complicated as those in mammals.

Because nitrate is the primary nitrogen source for plants, most studies on plant nitrogen sensing and signaling have focused on nitrate. Since nitrate can be readily converted into glutamine and glutamate, it is possible that many nitrogen responses triggered by inorganic nitrogen are in fact partly mediated by glutamine or glutamate. It is interesting that plant PII proteins have been recently demonstrated to sense glutamine to regulate the

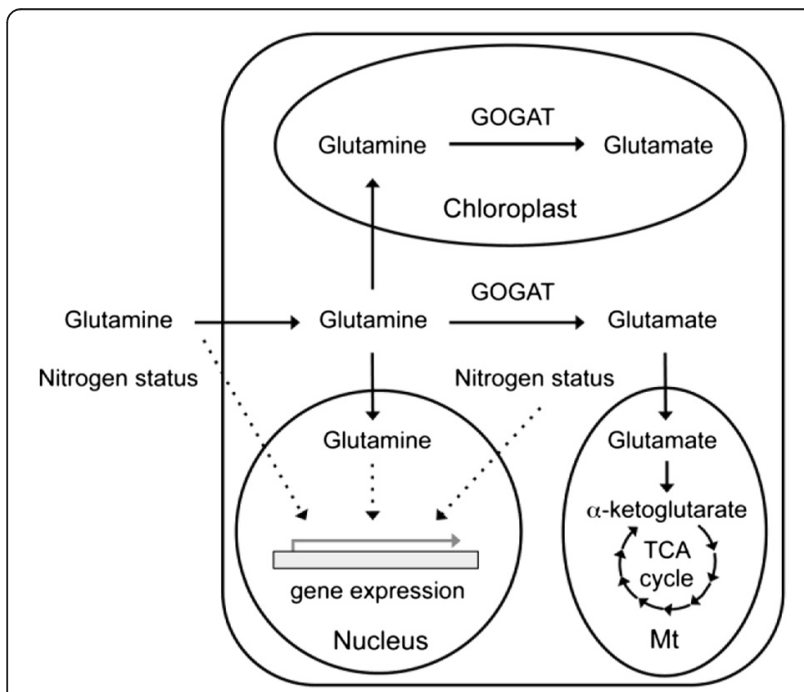

Fig. 5 Glutamine may function as a signaling nutrient in plants. Glutamine entering the plant cell can be directly used for metabolism to support plant growth and development. The internal glutamine and nitrogen status may affect gene expression in the nucleus. In addition, plants may be able to sense the external glutamine and nitrogen status to regulate gene expression. GOGAT glutamine oxoglutarate aminotransferase, TCA tricarboxylic acid, Mt mitochondrion activity of NAGK and the production of arginine and polyamine [14]. The functions of glutamine and the other amino acids likely go beyond that of metabolic regulation in plants. Further studies on the physiological roles and the sensing mechanisms of each amino acid are required to advance our knowledge of these processes in plants.

\section{Conclusion}

Increasing evidence shows that glutamine, the most abundant free amino acid in humans, plays critical roles in nutrition, metabolism, and signaling in mammals [16]. Glutamine is also one of the most abundant free amino acids in plants, and is important for protein and nucleotide synthesis. Here, we showed that glutamine might play a role in plant nutrition, and potentially function as a signaling molecule to regulate the expression of key transcription factor genes involved in nitrogen and stress responses (Fig. 5). The functions of early glutamineresponsive genes are very diverse, including metabolism, transport, signal transduction, and stress responses. Almost one-third of the early glutamine- responsive genes identified here encode transcription factors, indicating that glutamine may efficiently amplify its signal and interact with the other signal transduction pathways to regulate plant growth and stress responses. Thus, glutamine is an important nutrient and a functional amino acid in plants.

\section{Availability of supporting data}

The data set supporting the results of this article is available in the NCBI GEO repository [http://www.ncbi.nlm. nih.gov/geo/query/acc.cgi?acc=GSE56770].

\section{Additional file}

Additional file 1: Table S1. Primers used for RT-PCR analysis of glutamine-responsive genes. Table S2. Primers used for quantitative RT-PCR analysis of glutamine-responsive transcription factor genes. Figure S1. Effects of alanine and glycine on the growth of rice seedlings. Figure S2. Amino acid sequence alignment of Arabidopsis LBD37 and its rice orthologs Os03g0445700 and Os07g0589000. (PDF 2445 kb)

\section{Abbreviations}

GS: Glutamine synthetase; GOGAT: Glutamine-oxoglutarate aminotransferase; NAGK: N-acetyl-glutamate kinase; mTORC1: Mammalian target of rapamycin complex 1; RT-PCR: Reverse transcription-polymerase chain reaction; RR: Response regulator; PUP: Purine transporters; ROS: Reactive oxygen species.

\section{Competing interests}

The authors declare that they have no competing interests.

\section{Authors' contributions}

CCK, TYC and MHH conceived and designed the experiments. CCK, TYC and YAJ conducted the experiments and analyzed the data. MHH wrote the paper. All authors read and approved the final manuscript. 


\section{Acknowledgements}

This research was supported by grants from National Science Council (102-2311-B-001-002) and Academia Sinica (AS-103-SS-A03, 98-CDA-L04), Taipei, Taiwan. We thank Kuan-Lin Her and Shi-Kat Wong for technical assistance.

\section{Received: 30 April 2015 Accepted: 1 September 2015} Published online: 25 September 2015

\section{References}

1. Xu G, Fan X, Miller AJ. Plant nitrogen assimilation and use efficiency. Annu Rev Plant Biol. 2012;63:153-82.

2. Lea PJ, Miflin BJ. Alternative route for nitrogen assimilation in higher plants. Nature. 1974;251:614-6.

3. Ireland RJ, Lea PJ. The enzymes of glutamine, glutamate, asparagine, and aspartate metabolism. In: Singh BK, editor. Plant amino acids, biochemistry and biotechnology. New York: Marcel Dekker; 1999. p. 49-109.

4. Foyer CH, Bloom AJ, Queval G, Noctor G. Photorespiratory metabolism: genes, mutants, energetics, and redox signaling. Annu Rev Plant Biol. 2009;60:455-84.

5. Nasholm T, Kielland K, Ganeteg U. Uptake of organic nitrogen by plants. New Phytol. 2009;182:31-48.

6. Forde BG, Lea PJ. Glutamate in plants: metabolism, regulation, and signaling. J Exp Bot. 2007:58:2339-58.

7. Forchhammer K. Glutamine signaling in bacteria. Front Biosci. 2007;12:358-70

8. Arcondéguy $T$, Jack R, Merrick M. PII signal transduction proteins: pivotal players in microbial nitrogen control. Microbiol Mol Biol Rev. 2001;65:80-105.

9. Zhang Y, Pohlmann EL, Serate J, Conrad MC, Roberts GP. Mutagenesis and functional characterization of the four domains of $\mathrm{G} \ln D$, a bifunctional nitrogen sensor protein. J Bacteriol. 2010;192:2711-21.

10. Hsieh MH, Lam HM, van de Loo FJ, Coruzzi G. A Pll-like protein in Arabidopsis: putative role in nitrogen sensing. Proc Natl Acad Sci U S A. 1998:95:13965-70.

11. Hsieh MH, Goodman HM. Molecular characterization of a novel gene family encoding ACT domain repeat proteins in Arabidopsis. Plant Physiol. 2002;130:1797-806

12. Sung TY, Chung TY, Hsu CP. Hsieh MH. The ACR11 encodes a novel type of chloroplastic $A C T$ domain repeat protein that is coordinately expressed with GLN2 in Arabidopsis. BMC Plant Biol. 2011;11:118.

13. Radchenko MV, Thornton J, Merrick M. Pll signal transduction proteins are ATPases whose activity is regulated by 2-oxoglutarate. Proc Natl Acad Sci U S A. 2013;110:12948-53.

14. Chellamuthu VR, Ermilova E, Lapina T, Lüddecke J, Minaeva E, Herrmann C, et al. A widespread glutamine-sensing mechanism in the plant kingdom. Cell. 2014;159:1188-99.

15. Chellamuthu VR, Alva V, Forchhammer K. From cyanobacteria to plants: conservation of Pll functions during plastid evolution. Planta. 2013;237:451-62.

16. Curi R, Newsholme P, Procopio J, Lagranha C, Gorjão R, Pithon-Curi TC. Glutamine, gene expression, and cell function. Front Biosci. 2007;12:344-57.

17. Brasse-Lagnel C, Lavoinne A, Husson A. Control of mammalian gene expression by amino acids, especially glutamine. FEBS J. 2009;276:1826-44.

18. Wullschleger $\mathrm{S}$, Loewith $\mathrm{R}$, Hall MN. TOR signaling in growth and metabolism. Cell. 2006:124:471-84.

19. Crespo JL, Powers T, Fowler B, Hall MN. The TOR-controlled transcription activators GLN3, RTG1, and RTG3 are regulated in response to intracellular levels of glutamine. Proc Natl Acad Sci U S A. 2002;99:6784-9.

20. Jewell JL, Kim YC, Russell RC, Yu FX, Park HW, Plouffe SW, et al. Differential regulation of mTORC1 by leucine and glutamine. Science. 2015;347:194-8.

21. Tabuchi M, Abiko T, Yamaya T. Assimilation of ammonium ions and reutilization of nitrogen in rice (Oryza sativa L.). J Exp Bot. 2007;58:2319-27.

22. Miller AJ, Fan X, Shen $Q$, Smith SJ. Amino acids and nitrate as signals for the regulation of nitrogen acquisition. J Exp Bot. 2008;59:111-9.

23. Lee RB, Purves JV, Ratcliffe RG, Saker LR. Nitrogen assimilation and the control of ammonium and nitrate absorption by maize roots. J Exp Bot. 1992;43:1385-96.

24. Muller B, Tilliard P, Touraine B. Nitrate fluxes in soybean seedling roots and their response to amino acids: an approach using ${ }^{15} \mathrm{~N}$. Plant Cell Environ. 1995:18:1267-79.

25. Rawat SR, Silim SN, Kronzucker HJ, Siddiqi MY, Glass ADM. AtAMT1 gene expression and $\mathrm{NH}_{4}^{+}$uptake in roots of Arabidopsis thaliana: evidence for regulation by root glutamine levels. Plant J. 1999;19:143-52.
26. Thornton B. Inhibition of nitrate influx by glutamine in Lolium perenne depends upon the contribution of the HATs to the total influx. J Exp Bot. 2004:55:761-9

27. Dluzniewska P, Gessler A, Kopriva S, Strand M, Novak O, Dietrich H, et al. Exogenous supply of glutamine and active cytokinin to the roots reduces $\mathrm{NO}_{3}^{-}$uptake rates in poplar. Plant Cell Environ. 2006;29:1284-97.

28. Fan X, Gordon-Weeks R, Shen Q, Miller AJ. Glutamine transport and feedback regulation of nitrate reductase activity in barley roots leads to changes in cytosolic nitrate pools. J Exp Bot. 2006;57:1333-40.

29. Vincentz M, Moureaux T, Leydecker MT, Vaucheret H, Caboche M. Regulation of nitrate and nitrite reductase expression in Nicotiana plumbaginifolia leaves by nitrogen and carbon metabolites. Plant J. 1993;3:315-24.

30. Sonoda Y, Ikeda A, Saiki S, Yamaya T, Yamaguchi J. Feedback regulation of the ammonium transporter gene family AMT1 by glutamine in rice. Plant Cell Physiol. 2003:44:1396-402.

31. Vidmar JJ, Zhuo D, Siddiqi MY, Schoerring JK, Touraine B, Glass ADM. Regulation of high affinity nitrate transporter genes and high affinity nitrate influx by nitrogen pools in plant roots. Plant Physiol. 2000;123:307-18.

32. Nazoa P, Vidmar JJ, Tranbarger TJ, Mouline K, Damiani I, Tillard P, et al. Regulation of the nitrate transporter gene AtNRT2.1 in Arabidopsis thaliana: responses to nitrate, amino acids and developmental stage. Plant Mol Biol. 2003;52:689-703.

33. Hirose $N$, Hayakawa T, Yamaya T. Inducible accumulation of mRNA for $\mathrm{NADH}$-dependent glutamate synthase in rice roots in response to ammonium ions. Plant Cell Physiol. 1997;38:1295-7.

34. Lam HM, Hsieh MH, Coruzzi G. Reciprocal regulation of distinct asparagine synthetase genes by light and metabolites in Arabidopsis thaliana. Plant J. 1998;16:345-53.

35. Oliveira IC, Coruzzi GM. Carbon and amino acids reciprocally modulate the expression of glutamine synthetase in Arabidopsis. Plant Physiol. 1999:121:301-9.

36. Liu G, Ji Y, Bhuiyan NH, Pilot G, Selvaraj G, Zou J, et al. Amino acid homeostasis modulates salicylic acid-associated redox status and defense responses in Arabidopsis. Plant Cell. 2010;22:3845-63.

37. Kamada-Nobusada T, Makita N, Kojima M, Sakakibara H. Nitrogen-dependent regulation of de novo cytokinin biosynthesis in rice: the role of glutamine metabolism as an additional signal. Plant Cell Physiol. 2013;4:1881-93.

38. Fukumorita T, Chino M. Sugar, amino acid, and inorganic contents in rice phloem sap. Plant Cell Physiol. 1982;23:273-83.

39. Yoshida S, Forno D, Cock J, Gomez K. Laboratory manual for physiological studies of rice. Manila, The Philippines: The International Rice Research Institute; 1976.

40. Tseng CC, Lee CJ, Chung YT, Sung TY, Hsieh MH. Differential regulation of Arabidopsis plastid gene expression and RNA editing in non-photosynthetic tissues. Plant Mol Biol. 2013;82:375-92.

41. Salazar C, Armenta JM, Shulaev V. An UPLC-ESI-MS/MS assay using 6-aminoquinolyl- $N$ hydroxysuccinimidyl carbamate derivatization for targeted amino acid analysis: application to screening of Arabidopsis thaliana mutants. Metabolites. 2012:2:398-428.

42. Rubin G, Tohge T, Matsuda F, Saito K, Scheible WR. Members of the LBD family of transcription factors repress anthocyanin synthesis and affect additional nitrogen responses in Arabidopsis. Plant Cell. 2009;21:3567-84

43. Albinsky D, Kusano M, Higuchi M, Hayashi N, Kobayashi M, Fukushima A, et al. Metabolomic screening applied to rice FOX Arabidopsis lines leads to the identification of a gene-changing nitrogen metabolism. Mol Plant. 2010;3:125-42.

44. Agarwal P, Arora R, Ray S, Singh AK, Singh VP, Takatsuji H, et al. Genomewide identification of $\mathrm{C}_{2} \mathrm{H} 2$ zinc-finger gene family in rice and their phylogeny and expression analysis. Plant Mol Biol. 2007;65:467-85.

45. Mao D, Chen C. Colinearity and similar expression pattern of rice DREB1s reveal their functional conservation in the cold-responsive pathway. PLoS One. 2012;7, e47275.

46. Takasaki H, Maruyama K, Kidokoro S, Ito Y, Fujita Y, Shinozaki K, et al. The abiotic stress-responsive NAC-type transcription factor OsNAC5 regulates stress-inducible genes and stress tolerance in rice. Mol Genet Genomics. 2010:284:173-83.

47. Song SY, Chen Y, Chen J, Dai XY, Zhang WH. Physiological mechanisms underlying OsNAC5-dependent tolerance of rice plants to abiotic stress. Planta. 2011;234:331-45.

48. Jeong JS, Kim YS, Redillas MCFR, Jang G, Jung H, Bang SW, et al. OsNAC5 overexpression enlarges root diameter in rice plants leading to enhanced drought tolerance and increased grain yield in the field. Plant Biotech J. 2013:11:101-14 
49. Ogo Y, Itai RN, Nakanishi H, Inoue H, Kobayashi T, Suzuki M, et al. Isolation and characterization of IRO2, a novel iron-regulated bHLH transcription factor in graminaceous plants. J Exp Bot. 2006;57:2867-78.

50. Ogo Y, Itai RN, Nakanishi H, Kobayashi T, Takahashi M, Mori S, et al. The rice bHLH protein OsIRO2 is an essential regulator of the genes involved in Fe uptake under Fe-deficient conditions. Plant J. 2007:51:366-77.

51. Ogo Y, Itai RN, Kobayashi T, Aung MS, Nakanishi H, Nishizawa NK. OsIRO2 is responsible for iron utilization in rice and improves growth and yield in calcareous soil. Plant Mol Biol. 2011;75:593-605.

52. Komatsu S, Takasaki H. Gibberellin-regulated gene in the basal region of rice leaf sheath encodes basic helix-loop-helix transcription factor. Amino Acids. 2009;37:231-8.

53. Rashid M, He G, Yang G, Hussain J, Xu Y. AP2/ERF transcription factor in rice: genome-wide canvas and syntenic relationships between monocots and eudicots. Evol Bioinform. 2012:8:321-55.

54. Kurusu T, Hamada J, Nokajima H, Kitagawa Y, Kiyoduka M, Takahashi A, et al. Regulation of microbe-associated molecular pattern-induced hypersensitive cell death, phytoalexin production, and defense gene expression by calcineurin B-like protein-interacting protein kinases, OsCIPK14/15, in rice cultured cells. Plant Physiol. 2010;153:678-92.

55. Xiang Y, Huang Y, Xiong L. Characterization of stress-responsive CIPK genes in rice for stress tolerance improvement. Plant Physiol. 2007;144:1416-28.

56. Jain M, Tyagi AK, Khurana JP. Molecular characterization and differential expression of cytokinin-responsive type-A response regulators in rice (Oryza sativa). BMC Plant Biol. 2006;6:1

57. Hirose N, Makita N, Kojima M, Kamada-Nobusada T, Sakakibara H. Overexpression of a type-A response regulator alters rice morphology and cytokinin metabolism. Plant Cell Physiol. 2007:48:523-39.

58. Rao KP, Richa T, Kumar K, Raghuram B, Sinha AK. In silico analysis reveals 75 members of mitogen-activated protein kinase kinase kinase gene family in rice. DNA Res. 2010;17:139-53.

59. Zhang S, Chen C, Li L, Meng L, Singh J, Jiang N, et al. Evolutionary expansion, gene structure, and expression of the rice wall-associated kinase gene family. Plant Physiol. 2005;139:1107-24

60. Pilot G, Stransky H, Bushey DF, Pratelli R, Ludewig U, Wingate VPM, et al. Overexpression of GLUTAMINE DUMPER1 leads to hypersecretion of glutamine from hydathodes of Arabidopsis leaves. Plant Cell. 2004:16:1827-40.

61. Pratelli R, Voll LM, Horst RJ, Frommer WB, Pilot G. Stimulation of nonselective amino acid export by glutamine dumper proteins. Plant Physiol. 2010;152:762-73.

62. Kiba T, Kudo T, Kojima M, Sakakibara H. Hormonal control of nitrogen acquisition: roles of auxin, abscisic acid, and cytokinin. J Exp Bot 2011;62:1399-409.

63. To JP, Haberer G, Ferreira FJ, Derue're J, Mason MG, Schaller GE, et al. TypeA Arabidopsis response regulators are partially redundant negative regulators of cytokinin signaling. Plant Cell. 2004;16:658-71.

64. Bürkle L, Cedzich A, Döpke C, Stransky H, Okumoto S, Gillissen B, et al. Transport of cytokinins mediated by purine transporters of the PUP family expressed in phloem, hydathodes, and pollen of Arabidopsis. Plant J. 2003:34:13-26.

65. Forsum O, Svennerstam H, Ganeteg U, Näsholm T. Capacities and constraints of amino acid utilization in Arabidopsis. New Phytol. 2008;179:1058-69.

66. Ho CH, Lin SH, Hu HC, Tsay YF. CHL1 functions as a nitrate sensor in plants. Cell. 2009:138:1184-94.

67. Wang S, Tsun ZY, Wolfson RL, Shen K, Wyant GA, Plovanich ME, et al. Lysosomal amino acid transporter SLC38A9 signals arginine sufficiency to mTORC1. Science. 2015;347:188-94.

\section{Submit your next manuscript to BioMed Central and take full advantage of:}

- Convenient online submission

- Thorough peer review

- No space constraints or color figure charges

- Immediate publication on acceptance

- Inclusion in PubMed, CAS, Scopus and Google Scholar

- Research which is freely available for redistribution

Submit your manuscript at www.biomedcentral.com/submit 